\title{
Multi-microelectrode devices for intrafascicular use in peripheral nerve
}

\author{
Wim L.C. Rutten \\ Institute for BioMedical Technology/ Faculty of Electrical Engineering \\ University of Twente, POBox 217,7500 AE Enschede, The Netherlands, rtn@el.utwente.nl
}

\begin{abstract}
This minisymposium paper gives an overview of experimental, modeling, design and microfabrication steps which lead towards the University of Twente threedimensional 128 -fold silicon microelectrode device. The device is meant for implantation in peripheral nerve for neuromuscular control purposes and is estimated to be able to selectively control 10-20 motor fibres.

Also, the potentialities of an alternative LIGA microfabrication technology are considered.

A brief comparison is made with the twodimensional sieve and flexible foil types of neuro electronic interfaces, under development elsewhere.

Microfabrication technologies appear to be an important tool, but evidence is accumulating that for selective neuroelectronic interfacing the micro devices are not yet small/selective enough. More precison and selectivity is needed to contact individual axons intimately and selectively. Therefore, new lines of research develop towards in-vitro-neuron-cultured MEP's (Multi Electrode Plates) to be implanted in neural tissue.
\end{abstract}

\section{THE UNIVERSITY OF TWENTE THREEDIMENSIONAL 128-MICROELECTRODE DEVICE}

\section{Experiments, modeling and design}

If selective contact of one-electrode-one-fiber is to be obtained, one has to bring an electrode close to one of the nodes of Ranvier of a fibre. The only 'garantuee' for that in a 'random' population of fibers is the use of a redundant number of electrodes in the nerve. For example, the peroneal nerve of the rat controls four muscles. One of these is the Extensor Digitorum Longum (EDL) muscle, with 70 motor units. Assuming a random topology for the position of the EDL motor fibres in the fascicle, one calculates that for the control of 10-20 fibres a number of 128 electrodes will be sufficient. Control of all 70 fibres would imply a multiple of 128 electrodes, which is not possible on a microfabrication scale $[4-13,21]$.

Experiments with a linear 12-fold silicon electrode array and a twodimensional 24-fold wire-array (Figure 1, [9]) in the peroneal nerve of rat, and volume conduction modeling studies, lead to the optimal dimensions for a 3D multi micro electrode with 128 electrode sites (Figs, 2 and 3) [4,5,14, $15,16]$.
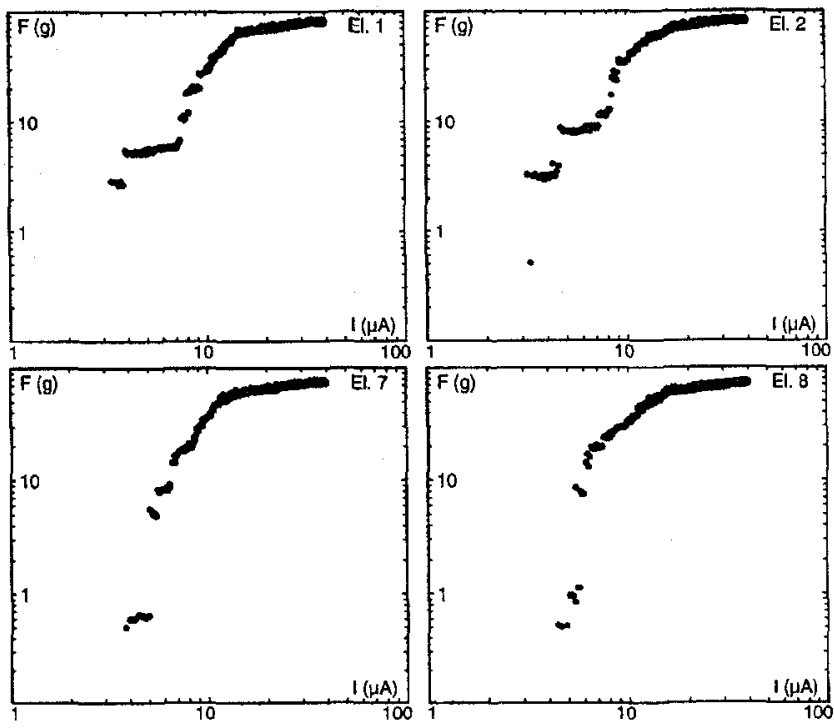

Figure 1. Twitch force recruitment curves of rat $\mathrm{EDL}$ muscle stimulated by a 24 -fold $2 \mathrm{D}$ electrode array (see inset), electrode spacing is $120 \mu \mathrm{m}$. Scales are log-log. Vertical scale ranges from 0.1 to 100 grams, horizontal from 1 to 100 $\mu$ A. Only 4 curves of the 24 are shown. See [9] for more detail.

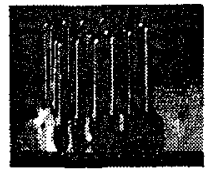

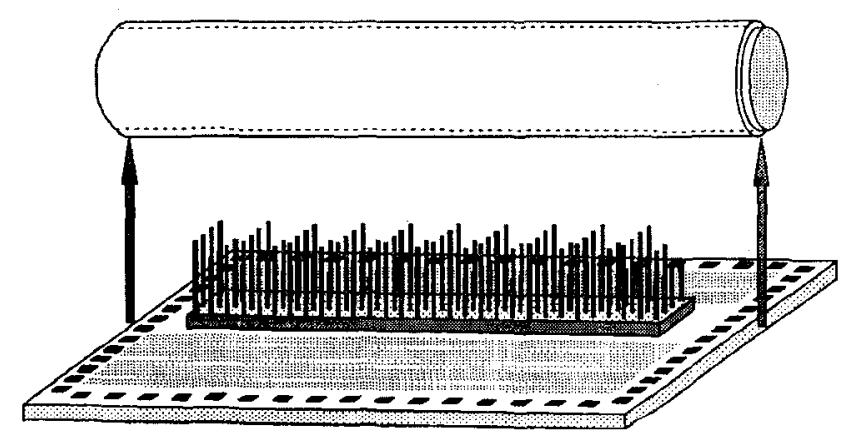

Figure 2. Schematic overview of a CMOS chip carrying a 3D array of 128 microelectrodes, to be inserted into a nerve. For dimensions, see Fig. 3.

\section{Microfabrication}

The fabrication of a 3D silicon based multi micro electrode involves a large number of challenging steps [14], not only for 
18th Annual International Conference of the IEEE Engineering in Medicine and Biology Society, Amsterdam 1996 M3: Minisymposium

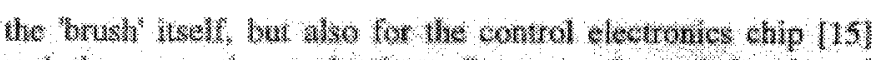

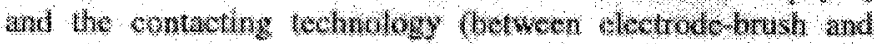
maxtateiplo6.

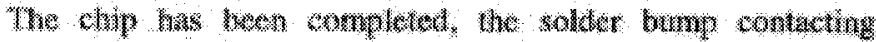

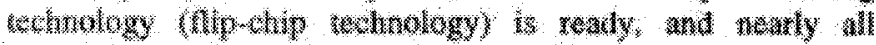

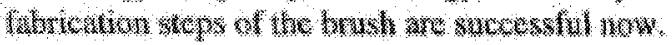

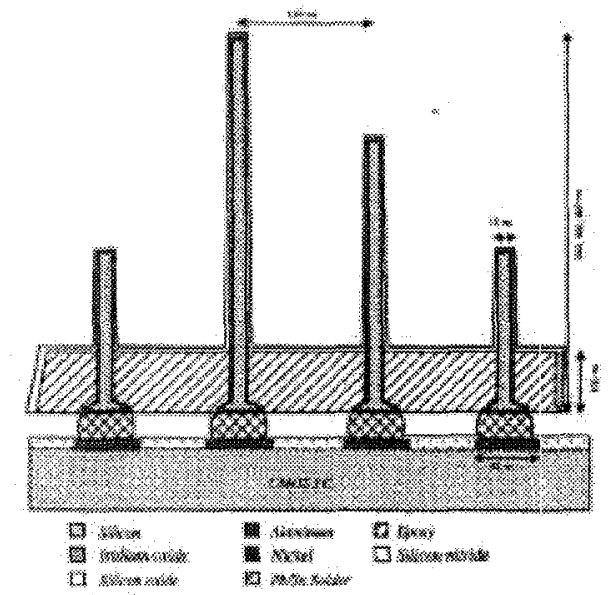

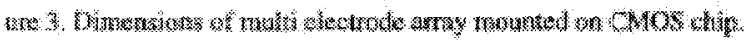

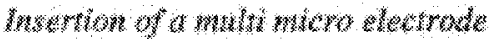

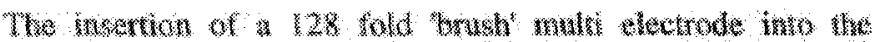

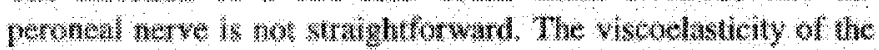

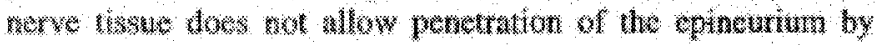

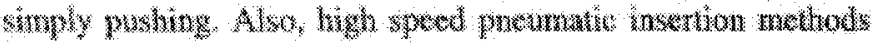
M.1.

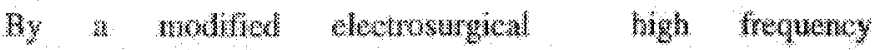
whw

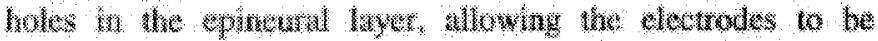

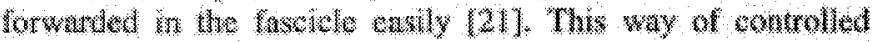

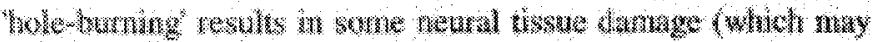

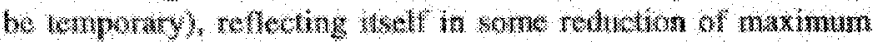
fork

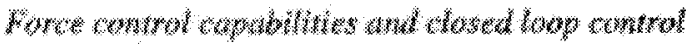

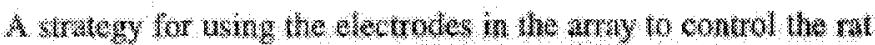

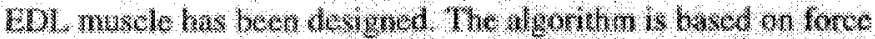

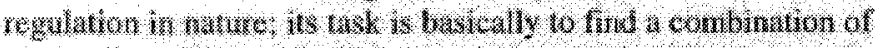

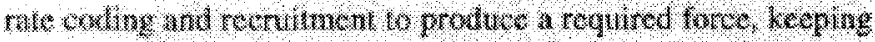

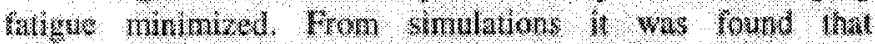

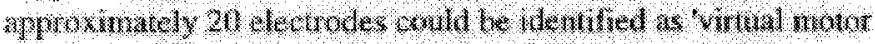

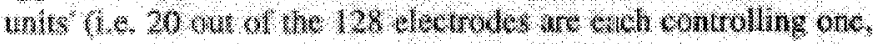

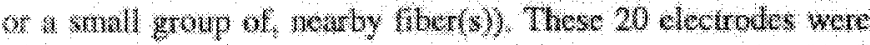

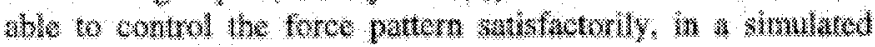
whonmont $[18\}$.

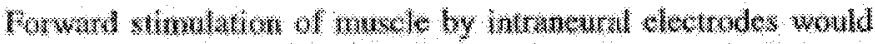

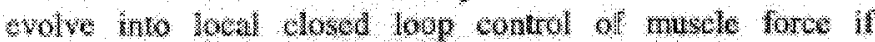

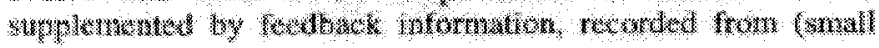

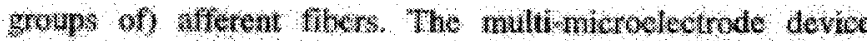

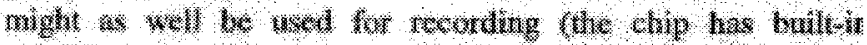

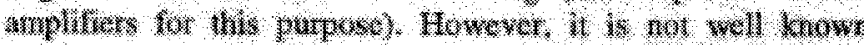

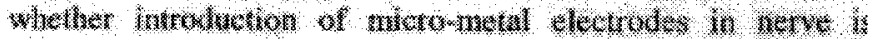

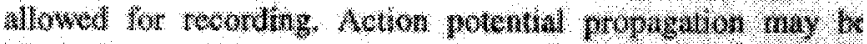

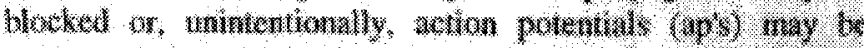

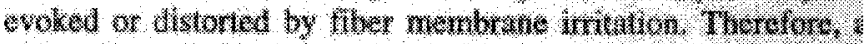

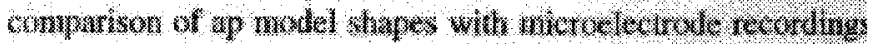

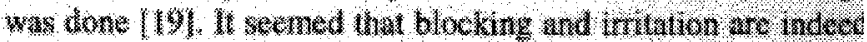

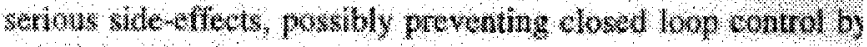

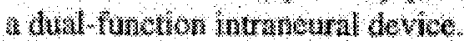

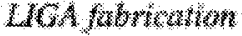

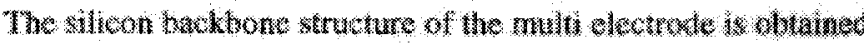

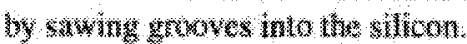

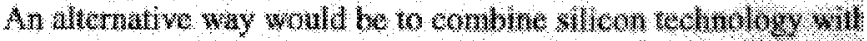

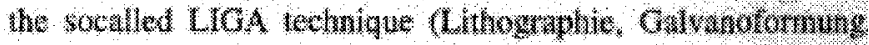

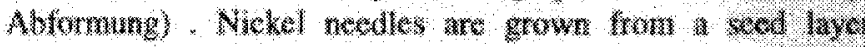

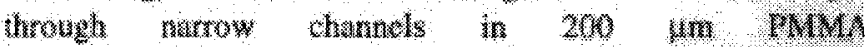

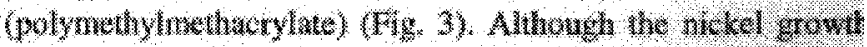

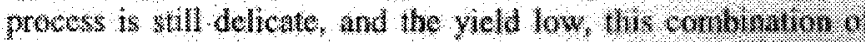

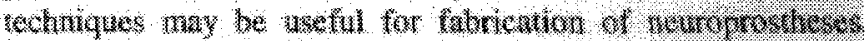

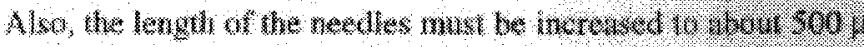
mas.

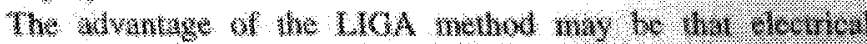

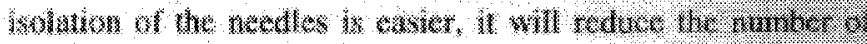
mowes werks

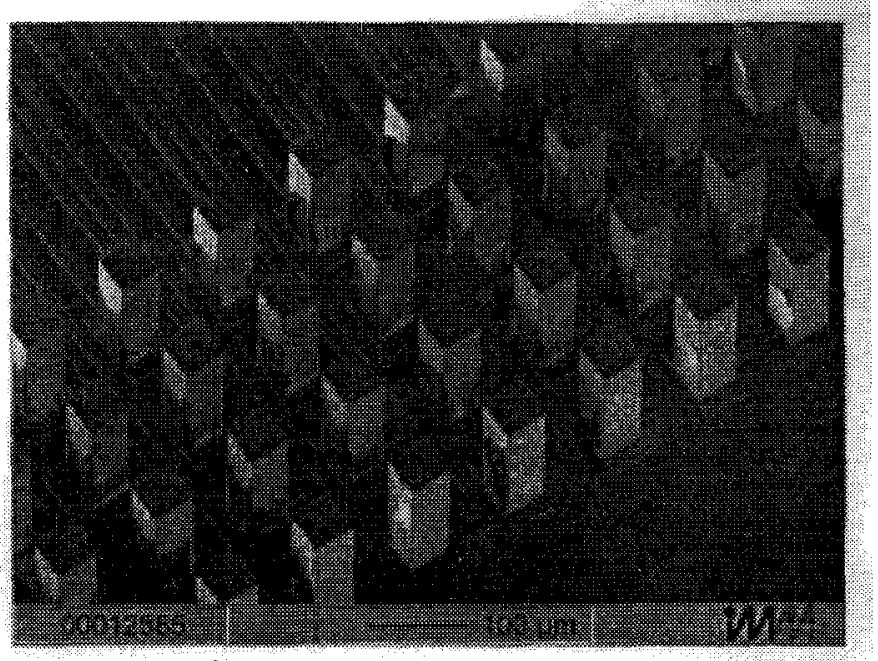

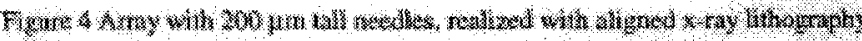

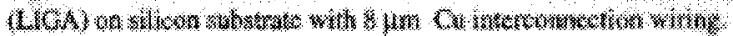

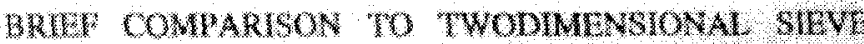

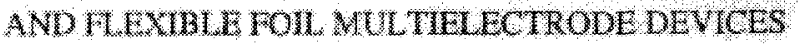

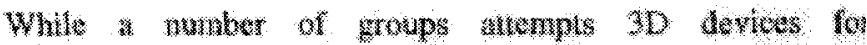

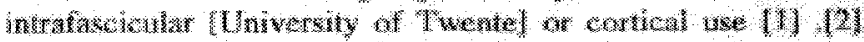


18th Annual International Conference of the IEEE Engineering in Medicine and Biology Society, Amsterdâm 1996 M3: Minisymposium

[University of Utah group], 2D devices offer a number of advantages.

Twodimensional 'sieve' devices permit nerve fibers to regenerate through the metalised via hole-electrodes of the sieve [3] [this conference: Univ. of Lund group, Fraunhofer Institute $\mathrm{St}$ Ingbert/Univ, of Barcelona group].

Main advantage of this method is that microfabrication of 'flat' devices is easier than $3 \mathrm{D}$ devices. Another advantage is that, once the nerve has been regenerated, the device is fixed firmly to the nerve. However, since the flats are typically only $10 \mu \mathrm{m}$ thick, there is a limited chance that nodes of Ranvier will be close to an electrode (typical internode spacing of a $10 \mu \mathrm{m}$ thick fiber is $1 \mathrm{~mm}$ ), thereby limiting the selectivity of stimulation/recording.

Another class of 2D electrodes are the flexible foil multi electrodes, which are intended for flat or bended use in between or around fascicles [this conference: Univ. of Aalborg group, Case Western Reserve Univ. Cleveland group, Fraunhofer Institute St Ingbert group]. Main difference with brush and sieve type is that they do not penetrate fascicles. This will limit fiber selectivity [19], but may enhance gross fascicular selectivity. Main advantage is the easy way of fabrication, which is essentially two-dimensional. Fixation of the flat type will need special attention.

\section{FUTURE DEVELOPMENTS: CULTURED MULTI ELECTRODE PLATES AS 'NEURAL PROBES'}

Our multielectrode device with 128 electrodes on top of 15-40 $\mu$ $\mathrm{m}$ thick tapered needles is expected to have an "efficiency' of 10-20 motor fibres to be contacted selectively. The device is not yet small/selective enough. However, one reaches the limit of what 3D microfabrication can offer.

Increase of efficiency is possible by a different approach. Instead of 'putting in more and more electrodes', the process is reversed: nerve fibres are 'seduced' to grow to electrodes, with natural cells as intermediates. The electrodes are covered (in the lab) by cultured nerve cells, which are grown in a controlled way on a chemically/topologically/electrically patterned Multi Electrode Plates (MEP) [22]. The cultured MEP is inserted/inplanted in the nerve (see also Pine's contribution on 'cultured probe' to this minisymposium).

\section{ACKNOWLEDGEMENTS}

The work of Jan Meier, Tom Rozijn, Jos Smit, Theo Frieswijk, Ton Verloop, Johan Bomer, Ed Droog, Jaap van Pelt, Jeroen Bielen, Anne Brouwer and many others at the University of Twente, the Netherlands' Institute for Brain Research and the Institut fur Mikrotechnik Mainz is gratefully acknowledged.

\section{REFERENCES}

[1] D.J.Edell, V.V.Toi, V.M.McNeil and L.D.Clark, "Factors influencing the biocompatibility of insertable silicon microshafts in cerebral cortex," IEEE Trans. Biomedical Engineering 39, 635-643, 1992.
[2] A.C.Hoogerwerf and K.D.Wise, A 3D microelectrode array for chronic neural recording, IEEE Trans. Biomedical Engineering 41, 1136-1146, 1994.

[3] G.T.A. Kovacs, C.W.Storment, M.Halks-Miller, C.R. Belczynski, C.C.Della Santina, E.R.Lewis and N.I.Maluf, "Silicon-substrate microelectrode arrays for parallel recording of neural activity in peripheral and cranial nerves, IEEE Trans. Biomedical Engineering 41, 567-577, 1994.

[4] W.L.C. Rutten, H. van Wier and J.H.M. Put. Sensitivity and selectivity of intraneural stimulation using a silicon electrode array.IEEE Transactions Biomedical Engineering, 1991, 192-198.

[5] J.H. Meier, "Selectivity and design of neuro-electronic interfaces", Ph.D. Thesis, University of Twente, Enschede, Netherlands, 1992.

[6] J.H. Meier, W.L.C. Rutten and H.B.K. Boom, Force recruitment during electrical nerve stimulation with multipolar intrafascicular electrodes, Medical \& biological engineering \& computing 33-3 (1995) 409-417.

[7] W.L.C. Rutten, T.A. Frieswijk, J.P.A. Smit, T.H. Rozijn and J.H. Meier, "3D Neuro-electronic interface devices for neuromuscular control: Design studies and realisation steps", Biosensors \& Bioelectronics, 10, 141-153, 1995. [8] T.A. Frieswijk and W.L.C. Rutten, "NEVIS: NEural VISualization of factors influencing force recruitment in intraneural stimulation", part I and Part II, Proc. 16th Ann. Int. Conf. IEEE Eng. Med. Biol. Soc., p. 359-362 1994 [9] J.P.A. Smit and W.L.C. Rutten, Intraneural stimulation using 2-D wiremicroelectrode arrays I. Experimental results, Proc. 17th Int Conf Eng in Med \& Biol., Montreal (1995), ISBN: CD-ROM 0-7803-2478-1, 4 p.

[10] J.P.A. Smit and W.L.C. Rutten, Intraneural stimulation using 2-D wire micro electrode arrays II. Comparison with single-wire electrode results, Proc. 17th Int Conf Eng in Med \& Biol.1 (1995), CD-ROM 0-7803-2478-1,4 p.

[11] J.H. Meier, W.L.C. Rutten , A.E. Zoutman, H.B.K. Boom and P. Bergveld. Simulation of multipolar fibre selective neural stimulation using intrafascicular electrodes. IEEE Trans Biomed Eng 39(2), 122-134, 1992.

[12] W.L.C. Rutten and J.H. Meier. Selectivity of intraneural prosthetic interfaces for muscular control. Medical \& Biological Engineering \& Computing 29(6), pp. NS3-NS7, 1991.

[13] W.L.C. Rutten, Neurostimulation and neurosensing with multicontaci neuro-electronic interfaces. Proc. 14th Ann. Int. Conf. IEEE Eng. Med. Biol. Soc., Satellite symposium on neuroscience and technology, Lyon, 2-4 november, 254-258, 1992.

[14] T.A. Frieswijk and W.L.C. Rutten, Three-dimensional neuroelectronic interface for peripheral nerve stimulation and recording: realization steps and contacting technology, Proc. 16th Ann. Int. Conf. IEEE Eng. Med. Biol. Soc., p. $361-362,1994$

[15] T.A. Frieswijk, W.L.C. Rutten, H.G. Kerkhoff and K. Lippe, Control electronics for a neuro-electronic interface implemented in a gate Array, Proc. I7th lnt Conf Eng in Med \& Biol., Montreal (1995), ISBN: CD-ROM 0-78032478-1, 2 p.

[16] T.A. Frieswijk, J.A. Bielen and W.L.C. Rutten, Development of a solder bump technique for contacting a three-dimensional multi electrode array, Proc. 17th Int Conf Eng in Med \& Biol., Montreal (1995), ISBN: CD-ROM 0-7803. 2478-1, 2 p.

[17] J.P.A. Smit and W.L.C. Rutten, A technique for electrically inserting electrode arrays into peripheral nerve, Proc. 16th Ann. Int. Conf. IEEE Eng. Med. Biol. Soc., (1994), 800-801

[18] T.A.Frieswijk, F.Dijkstra and W.L.C. Rutten, Strategy for Control of Muscle force using a 3D Multi Electrode Array in Intraneural Stimulation, Proc. 18th Int Conf Eng in Med \& Biol., A'dam 1996), ISBN: CD-ROM , 2 p.

[19] W.L.C. Rutten and J.H. Meier, Intraneural recording for neuroprosthetic use: normal action potential shapes and blocking effects, Proc. 17th Int Conj Eng in Med \& Biol., Montreal (1995), ISBN: CD-ROM 0-7803-2478-1, 2 p. [20] J.A.Bielen, A.W. Schmidt, R.Weiel and W.Rutten, Fabrication of multi electrode array structures for intra-nenral stimulation: assessment of the LIGA method, Proc. 18th Int Conf Eng in Med \& Biol., Amsterdam (1996), 2 p.

[21] J.P.A. Smit, W.L.C. Rutten and H.B.K. Boom, Intraneural stimulation using Wire-Microelctrode Arrays: Analysis of Force Steps in Recruitmen! Curves, Proc. 18th Int Conf Eng in Med \& Biol., Amsterdam (1996), 2 p. [22] J.van Pelt, P. Wolters, D.van Veen,J.Bomers, W.L.C.

Rutten,H.Overdijk,G.Ramakers, Long-term multieelectrode registration of neuronal firing activity from rat cerebral cortex tissue in vitro, Proc. 18 th Int Conf Eng in Med \& Biol., Amsterdam (1996), ISBN: CD-ROM , 2 p. 